\title{
A pilot experience of common European infectious diseases curriculum for medical students: the IDEAL summer school
}

\author{
Caroline Charlier ${ }^{1,2,3}$, Federica I Wolf ${ }^{4}$, Erika Vlieghe ${ }^{5,6}$, Benjamin Planquette ${ }^{7}$, \\ Pierre Van Damme ${ }^{8}$, Katleen de Gaetano Donati ${ }^{14}$, Pierre Buffet ${ }^{1}$, Benoît Henry ${ }^{1}$, Muge \\ Cevik ${ }^{9}$, Clifford Leen ${ }^{9}$, Ian Laurenson ${ }^{9}$, Helen Cameron ${ }^{10}$, Joseph Ogavu ${ }^{11}$, Evelyn \\ Nabankema ${ }^{11}$, Venice Omona ${ }^{12}$, Pauline Valnaud ${ }^{1}$, Claire Mackintosh ${ }^{9}$, Ingólfur \\ Johannessen $^{9}$, Jean-Pierre Van geertruyden ${ }^{5}$, Claire Le Jeunne ${ }^{1,13}$ and Roberto Cauda ${ }^{14}$
}

${ }^{1}$ Paris Descartes University

${ }^{2}$ Necker-Enfants Malades, Institut Imagine, Assistance Publique- Hôpitaux de Paris, Paris-France ${ }^{3}$ Institut Pasteur, French National Reference Centre and WHO Collaborating Centre for Listeria, Biology of Infection Unit, Inserm U1117, Paris-France

${ }^{4}$ Sacro Cuore Universita, Institute of General Pathology Gemelli Hospital, Roma-Italy

${ }^{5}$ Global Health Institute, University of Antwerp, Antwerp-Belgium

${ }^{6}$ Department of General Internal Medicine, Infectious Diseases and Tropical Medicine, University Hospital Antwerp, Antwerp-Belgium

${ }^{7}$ Paris Descartes University, Department of Pneumology, Georges Pompidou European Hospital, Assistance Publique- Hôpitaux de Paris, Paris-France

${ }^{8}$ Centre for the Evaluation of Vaccination, Vaccine and Infectious Disease Institute, University of Antwerp, Antwerp-Belgium

${ }^{9}$ University of Edinburgh \& NHS Lothian Infection Service, Edinburgh-UK

${ }^{10}$ Aston University, Birmingham-UK

${ }^{11}$ Mother Kevin Postgraduate Medical School, St Francis hospital, Nsambya-Uganda

${ }^{12}$ Lacor Hospital, University of Gulu, Gulu-Uganda

${ }^{13}$ Department of Internal Medicine, Cochin Port Royal Hospital, Assistance Publique- Hôpitaux de Paris Paris-France

${ }^{14}$ Sacred Heart University, Institute of Infectious Diseases and Tropical Diseases Gemelli Hospital, RomaItaly

\section{Correspondence to:}

Caroline Charlier

Service de Maladies Infectieuses et Tropicales, Hôpital Necker Enfants Malades

149 rue de Sèvres 75015 Paris

Tel : 0033144495262

Fax : 0033144495440

Mail : caroline.charlier@aphp.fr

Key words: teaching, summer school, cooperation, Europe, Infectious Diseases 
Are we able to tackle the unprecedented global challenges in microbiology and infectious diseases? Uncontrolled antibiotic prescription and misuse led to the ever-rising emergence of multiresistant bacteria such as ESBL-producing enterobacteria, multi and extremely-resistant mycobacteria [1, 2]. Human activities, including extensive deforestation, and climate change have fueled the emergence of new pathogens like Zika virus, while massive migration and travel patterns, alongside other aspects of globalization, drive fast dissemination of these threats $[3,4]$.

To address this ever-evolving scenario, education of the 14,000 European medical students [5] is of paramount importance [6], and our teaching work urgently requires re-appraisal. In sharp contrast with the huge efforts conducted in the last decades improving European epidemiological surveillance, harmonizing antimicrobial susceptibility testing, developing joint therapeutic recommendations and research projects, European teaching initiatives have essentially stayed focused on postgraduate students. Undergraduate infectious diseases teaching remains heterogeneous in content, duration and methods, and is delivered at the local level without an inter-European emphasis. To foster students' awareness of the upcoming challenges and to teach ways for handling those issues, we need to create a single community and abolish the current barriers hampering the circulation of students or teachers among our institutions, like those raised by heterogeneous curricula (considering the ID could be taught from $3^{\text {rd }}$ to $6^{\text {th }}$ year undergraduate students), non-English-based teaching and subsequent non-recognition of foreign curricula by Medical schools. This strategy is fully supported by the 'European Society of Clinical Microbiology and Infectious Diseases Professional Affairs Subcommittee who stated in 2011 that "it should be possible to train in any region of the European Community, enjoying equivalent standards (...) with equivalent terms and conditions" [7].

Many aspects of infectious disease teaching can be largely improved. The subject of infectious diseases includes a wide array of knowledge such as epidemiology, physiology, clinical skills, microbiology and therapeutics. Therefore, it is often taught in a fragmented manner, largely lacking a global perspective of the interrelations crucial for strong comprehension. This was emphasized by Edgar Morin in his report on Education at the UNESCO in 1999: "We should teach methods of grasping mutual relations and reciprocal influences between parts and the whole in a complex world" [8]. The emergence of novel and re-emerging infectious agents demands specific information and communication skills that foster the concerted global approach which should become a specific teaching goal [9]. As a consequence, European students do not feel sufficiently prepared to prescribe antibiotics responsibly, as highlighted by a recent study performed among 7328 final year undergraduate students from 179 medical 
schools in 29 countries [10, 11]. Importantly, strong correlational evidence between the prevalence rates of resistant bacteria and lower preparedness scores/higher self-reported supports the needs for further education [11]. Last but not least, our students are not trained to address the challenges raised by anti-vaccine attitudes in many European countries, which leads to the re-emergence throughout the continent of preventable diseases like measles [12].

Therefore, we developed an international infectious diseases course that now involves six institutions from five countries (Paris Descartes University, France, Università Cattolica di Roma, Italy, NHS Lothian, UK, Antwerp University, Belgium, Mother Kevin Postgraduate Medical School, Nsambya, Uganda and Lacor hospital, Gulu, Uganda). The course was first built on an intensive common course for infectious diseases which is described in detail elsewhere [13]. We then developed an international summer school, as a part of an enlarged Erasmus+ long term partnership programme called IDEAL ('Infectious Diseases Europe Africa Learning'). It aims to synchronize European infectious diseases curricula and promote cooperation through the exchange of staff and expertise. The summer school has now been operating for 2 years and has been very successful. In this editorial, we aim to report this experience of implementing a unique European initiative, as a working model to address the medical challenges and better prepare future physicians.

\section{Implementation}

Grounds - The question of removing borders in European teaching has been long addressed since the Bologna declaration in 1999 and the following Bologna process [14] that led to various initiatives including the European Union Life Long Learning programme Med-MOTION that focused on removing barriers to mobility in medical studies [15]. In this setting, a core group consisting of teachers from Paris Descartes University, France, Università Cattolica di Roma, Italy, and the University of Edinburgh, United Kingdom, first built a common course of infectious diseases that is now annually offered to volunteer medical students from each institution. The course, called $\mathrm{I}^{3} \mathrm{DC}$ (International Intensive Infectious Diseases course), is recognized by each institution, credited by ECTS (European Credits Transfer System) and has been successfully running for 6 years so far, as previously reported [13]. Our group was then joined by partners from Antwerp University (also members of the Med-MOTION initiative) and two Ugandan institutions (Mother Kevin Post Graduate Medical School, Nsambya, and Lacor Hospital, Gulu, Uganda), fueling more ambitious initiatives including a joint international summer school offered to European students as a part of the IDEAL programme. 
Conception and implementation of the summer school — Two sessions were organized at Paris Université Paris Descartes, Ilumens Simulation Center in August 2017 and 2018. The teaching content was collegially chosen by the international team of teachers, covering a wide array of topics including emerging/severe infectious diseases, global health approaches, vaccination and prevention.

Blended "hands-on" learning methods were chosen, such as case-based clinical reasoning, procedural and high-fidelity simulation, team-based learning and serious games in small groups to promote practical training and foster exchanges [16]; Such approaches were recently described by students as the most useful to prepare junior doctors for practice [11]. A special emphasis was given to share various practices among European teachers and between European and Ugandan colleagues, to highlight similarities and differences in diagnostic approaches and specificities in the prevention, management and control of infections like tuberculosis, malaria or hemorrhagic fevers. The input of Ugandan colleagues was particularly appreciated, as they shared their first-hand experience of treating the vast spectrum of tropical diseases daily, under completely different conditions. The summer school was offered to $3^{\text {rd }}-5^{\text {th }}$ year European undergraduate medical students provided that they completed infectious diseases and microbiology teaching at their home institution. Each session was delivered in English by medical educators from all institutions including Ugandan, over five working days and 30 hours. Students were split into smaller groups of 6-7 students, mixing curriculum and institutions to maximize interactivity and learning [11]. Limited registration fees (300-400 euros) covered students' accommodation and meal costs. The students paid for their travel.

\section{How did it work?}

In total, 46 medical students from 12 institutions and 8 countries (United Kingdom, France, Italy, Belgium, Spain, Greece, Switzerland, and Germany) attended the summer school that took place on the last week of August 2017 and 2018. In both courses, 23 students were selected based on their motivation letter and curriculum, to maintain a small group approach which has been instrumental for the success of the course. Students were $3^{\text {rd }}(n=31 / 46,67 \%), 4^{\text {th }}(n=6$, $13 \%)$ and $5^{\text {th }}(\mathrm{n}=9,20 \%)$-year, with $37 \%$ being male $(17 / 46)$.

Students evaluated sessions through anonymized semi-quantitative questionnaires. Both courses received excellent evaluation scores in all domains: teaching approach, scientific content and teamwork. Students pointed out that the course structure not only addressed their 
needs as physicians-to-be but also fostered communication skills, as well as awareness of common knowledge (https://www.ideal-program.com/paris-2017.html). They evaluated the course as excellent $(11 / 23,48 \%$ in $2017 ; 18 / 21,86 \%$ in 2018$)$, very good $(12 / 23,52 \%$ in 2017 ; $2 / 21,10 \%$ in 2018$)$ or satisfactory $(1 / 21,4 \%$ in 2018). They all indicated that they would be happy to recommend the course to their colleagues. It should be emphasized that the event not only fostered fruitful discussions among students but also between students and teachers, providing grounds for networking and further mobility, as well as collaborative projects among teachers. Given the success of the event, a third session is planned to commence on the $26^{\text {th }}$ August 2019.

\section{How can this experience be transferred?}

The IDEAL summer school is to our knowledge a unique European initiative demonstrating the feasibility of implementing joint European teaching at the undergraduate level. Considering the 14,000 European medical students, 46 students might be considered as a drop in the ocean [5]; however, this pioneer experience could be a working model to promote internationalization in medical teaching across Europe, in our curricula. We assume that this joint European teaching program can be applied broadly across other academic disciplines such as emergency medicine, and extended to other audiences, such as postgraduate students, midwives or vocational paramedical professionals like nurses, and delivered in other languages. It could also be replicated in other institutions. As any supranational initiative, tremendous support of Universities, joint efforts of dedicated administrative staff and volunteer teachers will be needed. To create a community of educators sharing resources in infectious diseases, the IDEAL team delivers all teaching tools on a dedicated open-source web interface and creates an IDEAL Alumni network (http://ideal-program.com). We also welcome educators from other institutions in all new IDEAL events to-come, to foster both innovations in medical teaching as well as to spread collaborative approaches.

To conclude, this pilot experience turned out to be a working model to address the challenges we are facing in an ever-changing landscape of global health. It demonstrated our ability as European medical educators to overcome language and organizational barriers moving towards a paradigm of European-wide teaching that (i) better addresses students' needs and (ii) underpins high quality, safe exchange of information across the continents, thereby promoting excellent patient care by tomorrow's physicians. 


\section{Funding}

Financial and/or material support was received for this work : the IDEAL summer schools were funded by an Erasmus + long term strategic partnership grant (2017-2019), and took place at the Ilumens simulation platform (Porf. A. Tesnière http://ilumens.fr/).

We would like to thank all the teachers involved in the Summer school: Courtney Baldridge, Clémence Beydond, Lucillia Bezu, Louis Boyer, Thierry Bultez, Helen Cameron, Benjamin Chaigne, Jean-Marc Chapplain, Jérémie Cohen, Hélène Coignard, Guillaume Escouboué, Mélanie Fromentin, Katleen de Gaetano, Eve Jablon, Rachel Jamison, Elsa Kermorvant, Aymeric Lancelot, Paul Legendre, Jonathan London, Clémence Martin, Alexis Régent, Steeve Satti, Antoine Tesnière and Sabrina Van Ierssel.

\section{References}

1. World Health Organization. Antimicrobial resistance global action plan. World Health Organization Press, Geneva (Switzerland) (2014).

2. Woerther PL, Burdet C, Chachaty E, Andremont A. Trends in human fecal carriage of extended-spectrum beta-lactamases in the community: toward the globalization of CTX-M. Clin Microbiol Rev 26(4), 744-758 (2013).

3. Weaver SC, Reisen WK. Present and future arboviral threats. Antiviral Res 85(2), 328345 (2010).

4. Charlier C, Beaudoin MC, Couderc T, Lortholary O, Lecuit M. Arboviruses and pregnancy: maternal, fetal, and neonatal effects. Lancet Child Adolesc Health 1(2), 134146 (2017).

5. Eurostat. Students in tertiary education, 2012. http://ec.europa.eu/eurostat/statisticsexplained/index.php/File:Students_in_tertiary_education,_2012_(\%C2012\%B2019)_ YB2015.png (2015) (last accessed : 2019/01/01).

6. World Health Organization. The Evolving Threat of Antimicrobial Resistance: Options for Action. 2012. http://whqlibdoc.who.int/publications/2012/9789241503181_eng.pdf (2012) (last accessed : 2019/01/01).

7. Morin E. The seven complex lessons in Education for the future. UNESCO Conference http://unesdoc.unesco.org/images/0011/001177/117740eo.pdf) (1999) (last accessed 2019/01/01). 
8. Dyar OJ, Pulcini C, Howard P, Nathwani D. European medical students: a first multicentre study of knowledge, attitudes and perceptions of antibiotic prescribing and antibiotic resistance. The Journal of antimicrobial chemotherapy 69(3), 842-846 (2014).

* This work evaluated students perception towards antibiotic therapy and gaps of knowledge.

9. Dyar OJ, Nathwani D, Monnet DL et al. Do medical students feel prepared to prescribe antibiotics responsibly? Results from a cross-sectional survey in 29 European countries. J Antimicrob Chemother 73(8), 2236-2242 (2018).

** This important work provides a multicentric assessment of students perception of their preparedness towards antibiotic prescription in their future practice. it identifies areas requiring improvement, and underlines the striking relationship between antibiotic resistance and self-preparedness perception.

10. Dyar OJ, Hills H, Seitz LT, Perry A, Ashiru-Oredope D. Assessing the Knowledge, Attitudes and Behaviors of Human and Animal Health Students towards Antibiotic Use and Resistance: A Pilot Cross-Sectional Study in the UK. Antibiotics (Basel) 7(1), (2018).

11. Read RC, Cornaglia G, Kahlmeter G. Professional challenges and opportunities in clinical microbiology and infectious diseases in Europe. The Lancet. Infectious diseases 11(5), 408-415 (2011).

** This article points out the current situation of Infectious Diseases and clinical microbiologist physicians across Europe.

12. Antona D, Levy-Bruhl D, Baudon C et al. Measles elimination efforts and 2008-2011 outbreak, France. Emerg Infect Dis 19(3), 357-364 (2013).

13. Charlier C, Johannessen I, Mackintosh CL et al. International infectious diseases teaching to undergraduate medical students: A successful European collaborative experience. Med Teach 39(9), 981-986 (2017).

* This article provides an extensed description of the intensive course that, together with the summerschool, is the ground of the IDEAL programme.

14. European higher education area. European higher education area and bologna process. http://www.ehea.info/pid34247/how-does-the-bologna-process-work.html (29/08/2016) (last accessed 2019/08/01).

** This website provides documentation of the Bologna conference and process, which is the cornerstone of any current initiative toward higher quality and more compatible higher education systems across Europe. 
15. Med-Motion. Med-MOTION Medical students and staff on the move. https://www.uantwerpen.be/en/projects/med-motion/about-med-motion/ (2015) (last accessed 2019/01/01).

16. Hawkins D. A Team-based Learning Guide for Faculty in the health professions. Authorhouse LLC, Bloomington Indiana. 1, (2014). 